\title{
Stress Corrosion Cracking of Zircaloy-4 in Halide Solutions. Effect of Temperature
}

\author{
S.B. Farina ${ }^{a}$, G.S. Duffo ${ }^{a / b} *$ J.R. Galvele ${ }^{a / b}$ \\ ${ }^{a}$ Comisión Nacional de Energía Atómica, Depto. Materiales Av. Gral Paz. 1499, \\ (1650) San Martín, Buenos Aires, Argentina \\ ${ }^{b}$ Consejo Nacional de Investigaciones Científicas y Técnicas (Argentina)
}

Received: August 28, 2001; Revised: March 13, 2002

\begin{abstract}
Zircaloy-4 was found to be susceptible to stress corrosion cracking in $1 \mathrm{M} \mathrm{NaCl}, 1 \mathrm{M} \mathrm{KBr}$ and $1 \mathrm{M} \mathrm{KI}$ aqueous solutions at potentials above the pitting potential. In all the solutions tested crack propagation was initially intergranular and then changed to transgranular. The effect of strain rate and temperature on the SCC propagation was investigated. An increase in the strain rate was found to lead to an increase in the crack propagation rate. The crack propagation rate increases in the three solutions tested as the temperatures increases between 20 and $90{ }^{\circ} \mathrm{C}$. The Surface-Mobility SCC mechanism accounts for the observation made in the present work, and the activation energy predicted in iodide solutions is similar to that found in the literature.
\end{abstract}

Keywords: zirconium, zircaloy-4, stress corrosion cracking, pitting

\section{Introduction}

Zirconium has a high melting point, adequate strength, good thermal conductivity, low thermal expansion, low cross section for capture of thermal neutrons and excellent corrosion resistance. For this reason, $\mathrm{Zr}$ alloys are widely used in the nuclear industry for nuclear fuel cladding and structural components.

Zirconium is a highly reactive metal with great affinity for oxygen. When $\mathrm{Zr}$ is exposed to an oxygen-containing environment, an adherent, protective oxide film forms on its surface. This film is formed spontaneously in air or water at room temperature. As a consequence, $\mathrm{Zr}$ exhibits an excellent general corrosion resistance in many environments.

It is worth noticing that $\mathrm{Zr}$ resists stress corrosion cracking (SCC) in strongly aggressive reagents such as $\mathrm{H}_{2} \mathrm{~S}$, $\mathrm{NaOH}$ and $\mathrm{MgCl}_{2}{ }^{1}$ which induce SCC in other common metals and alloys. The high SCC resistance of $\mathrm{Zr}$ can probably be attributed to its high repassivation rate in aqueous solutions. Any fracture in the surface film quickly heals, provided that there is sufficient oxygen-containing species present. However, $\mathrm{Zr}$ is susceptible to SCC in environments such as neutral halide solutions ${ }^{2}, \mathrm{FeCl}_{3}$ or $\mathrm{CuCl}_{2}$ containing solutions ${ }^{3-5}$, methanol + halides ${ }^{6}$, concentrated nitric acid $^{7,8}$, halogen vapours ${ }^{9}$ and liquid mercury or cesium ${ }^{10}$. It should be noted that SCC does not necessarily occur in some of

*e-mail: duffo@cnea.gov.ar

Trabalho apresentado no IV Coloquio Latinoamericano de Fractura y Fatiga these environments unless additional specific conditions are met. For example, zirconium and its alloys undergo SCC in iodine vapor at temperatures up to $200{ }^{\circ} \mathrm{C}$ only in precracked specimens, while this requirement is not necessary above this temperature ${ }^{11}$. Moreover, SCC in neutral chloride solutions requires anodic polarization at potential above the pitting potential ${ }^{12}$.

Among the numerous factors that influence the SCC of zirconium and its alloys, metallurgical aspects such as alloy composition, texture, residual stress and irradiation; mechanical aspects such as stress, stress intensity and strain rate; and electrochemical variables such as the electrode potential can be mentioned. Temperature also plays an important role in SCC of $\mathrm{Zr}$ alloys.

Despite many different mechanisms have been proposed to explain the process that causes SCC, the problem is unsolved and still a matter of dispute. The present work is mainly oriented to determine the mechanism for SCC of zirconium alloys in halide solutions. To this purpose, SCC susceptibility of Zry-4 in $1 \mathrm{M} \mathrm{NaCl}, 1 \mathrm{M} \mathrm{KBr}$ and $1 \mathrm{M} \mathrm{KI}$ aqueous solutions as a function of the applied potential, the strain rate and the temperature (between 20 and $90{ }^{\circ} \mathrm{C}$ ) was studied.

\section{Experimental Method}

The samples used were $1 \mathrm{~mm}$ diameter wires of Zry-4. The chemical composition of the alloy was (weight per- 
cent): $\mathrm{Fe}, 0.25 ; \mathrm{Cr}, 0.13 ; \mathrm{Sn}, 1.74 ; \mathrm{O}, 0.13 ; \mathrm{H}, 0.0013 ; \mathrm{Zr}$, balance.

The specimens were degreased with boiling ethyl ether, dried with hot air and annealed in argon atmosphere $\left(240 \mathrm{~mm} \mathrm{Hg}\right.$ ) for $2 \mathrm{~h}$ at $750{ }^{\circ} \mathrm{C}$. The annealing was made in quartz tubes wrapping the samples with tantalum sheets to avoid contamination with silicon. After annealing, the samples were cooled down in the furnace for 24 hours. Prior to the tests, the wires were degreased with acetone and dried with hot air. To study the effect of the cooling rate, some wires were annealed for $2 \mathrm{~h}$ at $750{ }^{\circ} \mathrm{C}$ and water quenched.

The cell used was described in a previous paper ${ }^{13}$. The solutions used, $1 \mathrm{M} \mathrm{NaCl}, 1 \mathrm{M} \mathrm{KBr}$ and $1 \mathrm{M} \mathrm{KI}$ were prepared with analytical grade reagents and high purity water $(18 \mathrm{M} \Omega . \mathrm{cm})$. Electrode potentials were measured through a Luggin capillary with a saturated calomel electrode for the chloride solution and with a mercurous sulfate electrode for the other solutions to avoid contamination. All the potentials are reported in the normal hydrogen electrode (NHE) scale.

A LYP Electronica potentiostat and millivoltmeter was used in the present work. Before straining, the wires were allowed to reach a stationary corrosion potential after $15 \mathrm{~min}$ exposure to the solution. Afterwards, the chosen potential was applied to the static samples for only 2-3 min to avoid a heavy surface dissolution. Finally, the specimens were strained to fracture at the chosen potential and strain rate. All these tests were conducted at temperatures ranging from 20 to $90{ }^{\circ} \mathrm{C}$. After fracture, the specimens were observed with a scanning electron microscope (Philips SEM 500) and then metallografically mounted and sectioned in order to measure the crack depth. The mean crack propagation rate was calculated using two alternative methods. One was based on the SEM observations: the length of the brittle zone was measured on the fracture surface, and this value was divided by the straining time. The other was based on

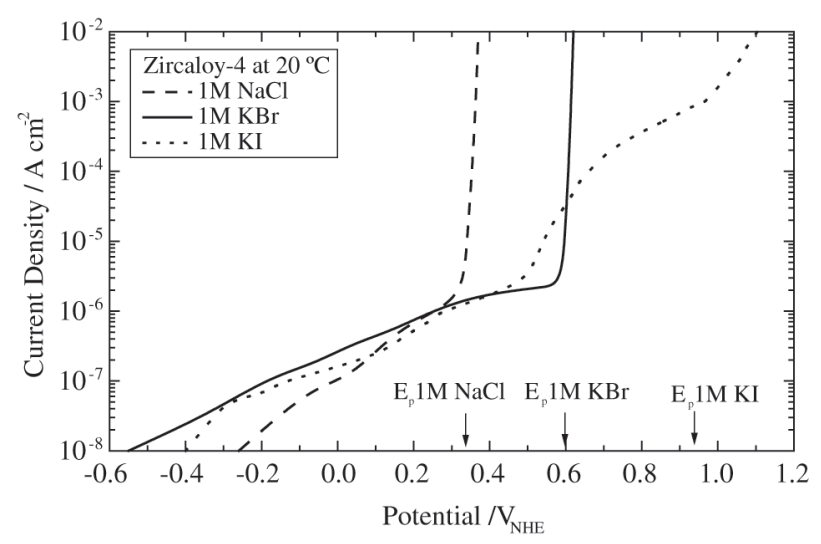

Figure 1. Typical anodic polarization curves for Zry-4 in deareated $1 \mathrm{M} \mathrm{NaCl}, 1 \mathrm{M} \mathrm{KBr}$ and $1 \mathrm{M} \mathrm{KI}$ solution at room temperature. metallographic observation: the length of the longest crack was divided by the straining time.

The anodic polarization curves were potentiodinamically measured starting from the rest potential at a potential scanning rate of $0.5 \mathrm{mV} \mathrm{s}^{-1}$. The solutions were deaerated with pre-purified Nitrogen, and after 2 hours deaeration period the polarization curves were drawn. These measurements were conducted with a PARC 173 potentiostat plus a PARC 175 potential scanner with a Houston X-Y recorder. A conventional three electrode glass cell with a capacity of $80 \mathrm{~cm}^{3}$ was used. The polarization curves were drawn at least by triplicate.

\section{Results and Discussion}

\section{Polarization curves}

Anodic polarization curves for Zry-4 were measured in $1 \mathrm{M} \mathrm{NaCl}, 1 \mathrm{M} \mathrm{KBr}$ and $1 \mathrm{M} \mathrm{KI}$ aqueous solutions at different temperatures between 20 and $90{ }^{\circ} \mathrm{C}$. Good reproducibility was found in the shape of the polarization curves and in the values of both, passive current densities and pitting potentials. Typical polarization curves at room temperature for Zry-4 in the three aqueous solutions mentioned above are shown in Fig. 1.

In the three solutions, a continuos and slight increase of the current density was observed as the potential was raised from the corrosion potential. There was a wide range of passivity in which the current densities varied from approximately $10^{-8} \mathrm{~A} \cdot \mathrm{cm}^{-2}$ to $10^{-6} \mathrm{~A} \cdot \mathrm{cm}^{-2}$. If the electrode potential was increased further the current density increased abruptly above a certain potential, usually called the pitting potential, as a result of the localized dissolution of $\mathrm{Zr}$ at pits. The pitting potentials $\left(\mathrm{E}_{\mathrm{p}}\right)$ are: $0.33 \mathrm{~V}_{\mathrm{NHE}}$ in $1 \mathrm{M} \mathrm{NaCl}$ solution, $0.6 \mathrm{~V}_{\mathrm{NHE}}$ in $1 \mathrm{M} \mathrm{KBr}$ solution and $0.94 \mathrm{~V}_{\mathrm{NHE}}$ in $1 \mathrm{M} \mathrm{KI}$ solution. It should be noted that the first increase in current density in the KI solution (at approximately $0.45 \mathrm{~V}_{\mathrm{NHE}}$ ) is due to the oxidation of iodide to iodine ${ }^{14,15,16}$, which is evidenciated by the fact that the solution turned yellowish.

Static samples polarized at a constant potential below the pitting potential $(<50 \mathrm{mV})$ showed no evidence of attack. On the other hand, when the applied potential was above the pitting potential the surface of the samples showed extensive pitting that developed at grain boundaries.

It was found that increasing the temperature between 20 and $90{ }^{\circ} \mathrm{C}$ had no effect on the anodic behavior of the material because the shapes of the polarization curves were very similar in that temperature interval. The only difference found was that the higher the temperature, the higher the passive current density. The invariability of pitting potentials was independent of temperature between 20 and $90{ }^{\circ} \mathrm{C}$. This behavior was similar to that reported by Beck ${ }^{17}$ for titanium in bromide solutions (between 30 and $185^{\circ} \mathrm{C}$ ) and iodide solutions (between 45 and $100{ }^{\circ} \mathrm{C}$ ). 


\section{Strain Rate Tests}

To study the effect of the applied potential on the SCC susceptibility of Zry-4 in the halide solutions at an initial strain rate of $4.6 \times 10^{-6} \mathrm{~s}^{-1}$, the elongation to rupture was measured for a wide range of applied potentials in the three solutions (Fig. 2).

In the three solutions, it was observed that when the applied potential was below the pitting potential, the elongation to rupture was the same as in air and no SCC was found. At potentials above the pitting potential, a sharp decrease in the elongation to rupture showed the existence of SCC. The fracture surfaces of these specimens showed little reduction in area, and a mixed morphology. There was a initial zone of intergranular (IG) cracking, followed by a zone of transgranular (TG) fracture and a final ligament that broke in ductile way. The surface appearance of a sample of Zry-4 polarized al $0.62 \mathrm{~V}_{\mathrm{NHE}}$ in a $1 \mathrm{M} \mathrm{KBr}$ solution is shown in Fig. 3. Cracking initiation is purely intergranular and then a transition to transgranular propagation occurred (Fig. 4). No differences were found using aerated and deaerated solution, neither in the elongation to rupture nor in the crack morphology.

The results found in the literature regarding the crack morphology of Zircaloys in chloride media are contradictory. $\mathrm{Cox}^{2}$ reported transgranular cracks for pre-cracked Double Cantilever Beam (DCB) specimens of Zry-2 in aqueous solutions of $\mathrm{NaCl}$ and Mankowski et al. ${ }^{18}$ also found the same result using the slow strain rate technique in $5 \%$ $\mathrm{NaCl}$ at room temperature. However, Cragnolino ${ }^{12}$ reported intergranular and transgranular cracking of Zry-4 in $\mathrm{NaCl}$ solutions. In solutions of ferric chloride and at constant load test, Thomas et al. ${ }^{4}$ and Bogoyavlenskii et al. ${ }^{5}$ reported exclusively intergranular cracking, but it should be noted that

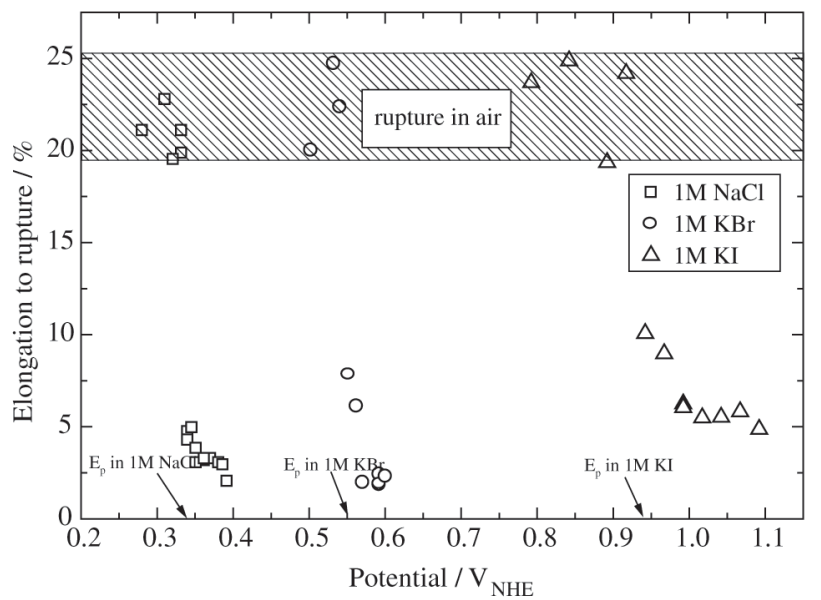

Figure 2. Elongation to rupture for Zry-4 strained at a strain rate of $4.6 \times 10^{-6} \mathrm{~s}^{-1}$ in $1 \mathrm{M} \mathrm{NaCl}, 1 \mathrm{M} \mathrm{KBr}$ and $1 \mathrm{M} \mathrm{KI}$ at room temperature as a function of the applied potential. in one of these papers ${ }^{4}$ only metallographic observations were reported, being difficult to asses if a transition IG-TG took place.

The apparent contradictory results for the initiation stage (IG vs. TG) may be understandable in terms of the specimens thermal treatment, in particular the cooling rate following the annealing treatment, because slow cooling rates may cause segregation of impurities to grain boundaries that could induce the initiation of IG attack. However, in the present work, the elongation to fracture and the crack morphology obtained in the three solutions with Zry-4 wires annealed and water quenched were similar to those obtained with furnace cooled samples. These results permit us to infer that the initial IG cracking is not due to changes pro-

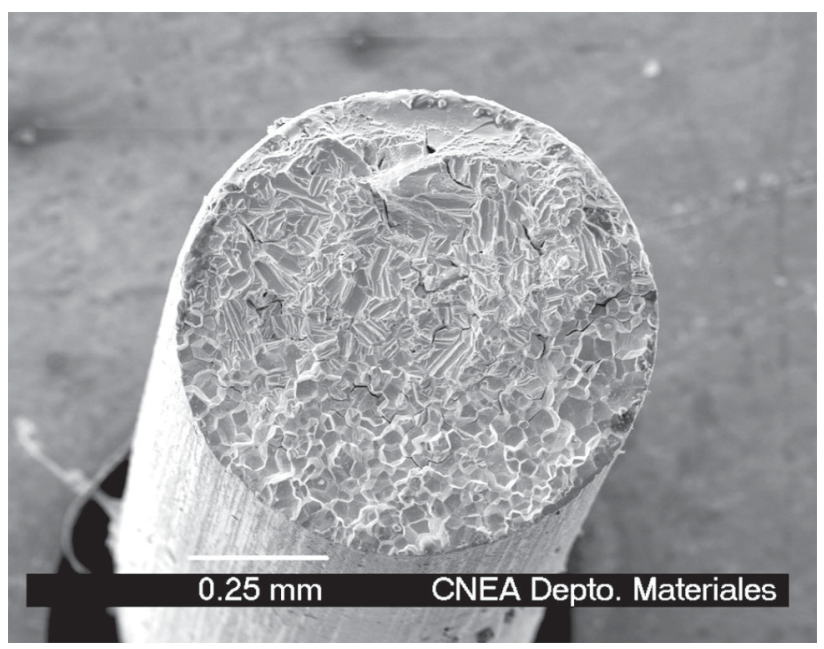

Figure 3. A typical fracture surface of Zry-4 wire strained at room temperature in a $1 \mathrm{M} \mathrm{KBr}$ solution at $0.62 \mathrm{~V}_{\mathrm{NHE}}$. Strain rate: $4.6 \times 10^{-6} \mathrm{~s}^{-1}$.

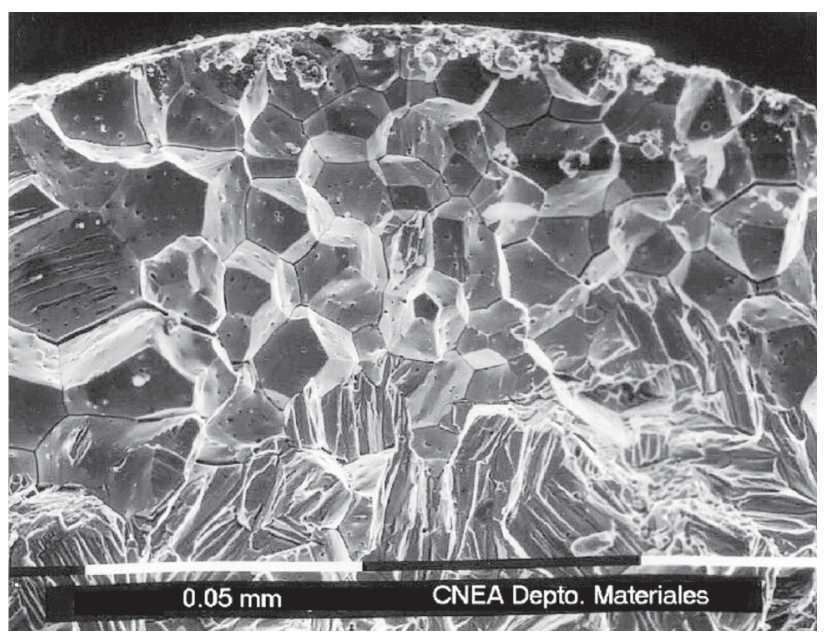

Figure 4. Transition zone between IG and TG modes of cracking. Zircaloy-4 in $1 \mathrm{M} \mathrm{KBr}$ solution at $0.62 \mathrm{~V}_{\mathrm{NHE}}$. Strain rate: $7.6 \times 10^{-4} \mathrm{~s}^{-1}$. 
duced in the grain boundary regions during the cooling of the samples.

The crack propagation rate (cpr) values found in the present work are shown in Fig. 5. In chloride and bromide solutions, the crack velocity increases slightly near the pitting potential and reaches a value of $10^{-7} \mathrm{~m} / \mathrm{s}$. In iodide solutions, the crack velocity is little affected by the applied potential and its value is approximately $5 \times 10^{-8} \mathrm{~m} / \mathrm{s}$. It should be noted that the number of data points in Fig. 5 differs from Fig. 2 due to the fact that some data points overlap.

It was not possible to resolve the separation between the rates of IG and TG stages, but the following speculation was made: in all cases, the fracture surfaces showed an IG zone with corrosion attack, while the TG zone did not show traces of corrosion attack. This led to the suggestion that the rate of IG cracking is lower than the TG propagation rate, being the IG cracking the rate controlling step of the overall process.

The effect of the strain rate on the crack propagation rate was also investigated. To this purpose, Zry-4 wires were tested at different strain rates (from $4.6 \times 10^{-6} \mathrm{~s}^{-1}$ to $2.5 \times 10^{-2} \mathrm{~s}^{-1}$ ), at room temperature, and at potentials $20 \mathrm{mV}$ above the respective pitting potential in each solution. The results are shown in Fig. 6. The crack velocity was found to increase monotonically with strain rate. Furthermore, the accelerating effect of the applied strain rate on the crack velocity was found to be nearly the same in the three solutions, slopes between 0.57 and 0.77 were calculated in Fig. 6. It is worth noticing that the crack morphology did not change with strain rate, the fracture surfaces were found to be intergranular and transgranular.

The effect of the temperature on the crack velocity was investigated in the $20-90{ }^{\circ} \mathrm{C}$ range. Tests were performed at

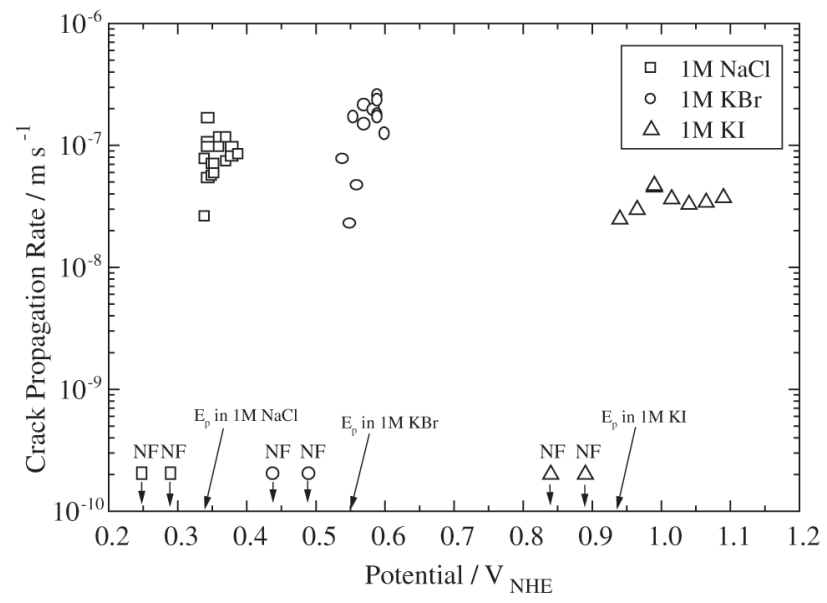

Figure 5. Crack propagation rate as a function of the electrode potential for Zry-4 wires strained in $1 \mathrm{M} \mathrm{NaCl}, 1 \mathrm{M} \mathrm{KBr}$ and $1 \mathrm{M}$ KI solutions at room temperature. Strain rate: $4.6 \times 10^{6} \mathrm{~s}^{-1}$. NF: no cracks detectable. constant low strain rate $\left(4.6 \times 10^{-6} \mathrm{~s}^{-1}\right)$ and at applied potentials $20 \mathrm{mV}$ above the respective pitting potentials in each solution. The results are shown in Fig. 7. Temperature was found to have little effect on the crack propagation rate in the three solutions tested. The activation energies calculated in the present work are: $11.7 \mathrm{~kJ} / \mathrm{mol}$ in $1 \mathrm{M} \mathrm{NaCl}$ solution; $7.5 \mathrm{~kJ} / \mathrm{mol}$ in $1 \mathrm{M} \mathrm{KBr}$ solution and $12.5 \mathrm{~kJ} / \mathrm{mol}$ in $1 \mathrm{M}$ KI solution.

In the present work (no matter the applied potential, the strain rate and the temperature) the following steps were always found in the three solutions: first electrochemical breakdown of the passive film by the application of a potential above the pitting potential, followed by intergranular cracking; then a transition from intergranular to transgranular cracking and a rapid transgranular propaga-

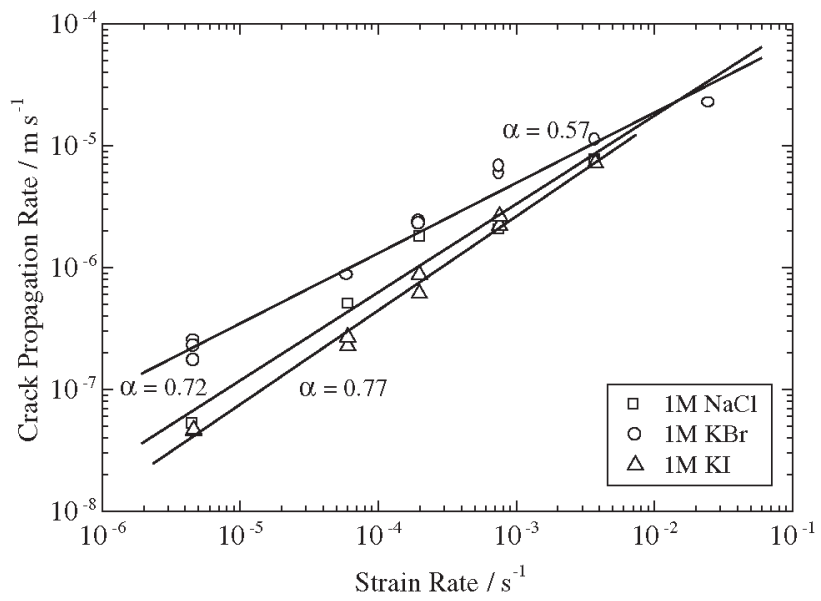

Figure 6. Crack propagation rate as a function of the strain rate for Zry-4 in $1 \mathrm{M} \mathrm{NaCl}, 1 \mathrm{M} \mathrm{KBr}$ and $1 \mathrm{M} \mathrm{KI}$ solutions at room temperature and potential $20 \mathrm{mV}$ above $\mathrm{E}_{\mathrm{p}}$ as indicated in Fig. 1.

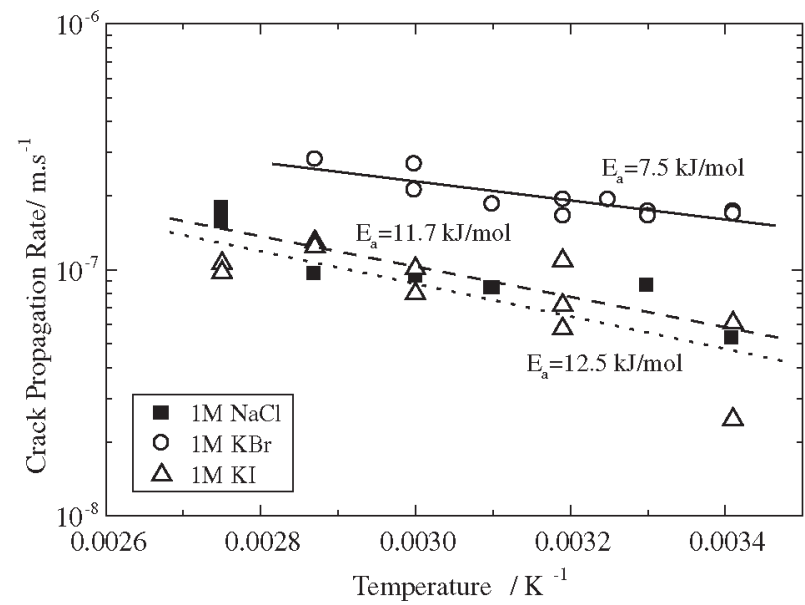

Figure 7. Crack propagation rate as a function of temperature for Zry-4 in $1 \mathrm{M} \mathrm{NaCl}, 1 \mathrm{M} \mathrm{KBr}$ and $1 \mathrm{M} \mathrm{KI}$ solutions. Strain rate: $4.6 \times 10^{-6} \mathrm{~s}^{-1}$, and potential $20 \mathrm{mV}$ above $\mathrm{E}_{\mathrm{p}}$ as indicated in Fig. 1. 
tion. The length of the IG and TG penetration was measured in all cases and it was found that the ratio IG/TG was almost constant.

There still remains the question whether the IG propagation is due to anodic dissolution assisted by stresses or a genuine IG SCC. At this respect, the dependence of the crack propagation rate on strain rate (SR) as given by the slope of $\log$ cpr vs. $\log$ SR is similar to those reported ${ }^{19,20}$ for the IG SCC of several alloys, thus indicating an IG SCC process. On the other hand, the activation energies found in the systems studied in the present work are consistent with an anodic dissolution process of $\mathrm{Zr}^{21}$ (between 7.9 and $11.3 \mathrm{~kJ} \mathrm{~mol}^{-1}$ ) and the fact that in static samples at potential above the pitting potential, pits developed at grain boundaries, would indicate that this step is IG attack (by anodic dissolution) assisted by stresses ${ }^{22}$.

Assuming that IG cracking is merely IG attack assisted by stresses and induced by anodic dissolution, then, TG cracking becomes the "true" SCC process. Following, the Surface-Mobility SCC mechanism will be applied to explain the results obtained in the present work.

According to the Surface-Mobility-SCC mechanism ${ }^{23}$, environmentally induced crack propagation is due to the capture of vacancies by the stressed lattice at the tip of the crack. The rate controlling step is the rate of movement of the vacancies along the surfaces of the crack, and the role of the environment is to change the surface self-diffusivity of the metal. It is known that low melting point contaminants formed on the surface increase the surface mobility and therefore enhanced SCC. In the present case, the low melting point compound formed would be the circonium tetrahalide hence Surface-Mobility-SCC should be expected.

With the above mentioned mechanism, the cpr can be predicted by the following equation ${ }^{23}$ :

$$
c p r=\frac{D_{s}}{L}\left[\exp \left(\frac{\sigma \cdot a^{3}}{k \cdot T}\right)-1\right]
$$

where $D_{S}$ is the surface self diffusion coefficient; $L$ is the diffusion distance of the vacancies (typically $10^{-8} \mathrm{~m}$ ); $\sigma$ the elastic surface stress at the tip of the crack; a the atom size; $\mathrm{k}$ the Boltzmann constant and $\mathrm{T}$ the absolute temperature. To estimate the $\mathrm{D}_{\mathrm{S}}$ value the following equation, developed by Gjostein ${ }^{24}$ and Rhead ${ }^{25,26}$ is used:

$$
D_{S}=740 \times 10^{-4} \exp -\left(30 T_{m} / R T\right)+0.014 \times 10^{-4} \exp -\left(13 T_{m} / R T\right)
$$

where $D_{S}$ is given in $\mathrm{m}^{2} / \mathrm{s}, \mathrm{R}$ is the gas constant $(1.987$ cal $\mathrm{mol}^{-1} \mathrm{~K}^{-1}$ ), $\mathrm{T}$ the absolute temperature and $\mathrm{T}_{\mathrm{m}}$ the melting point of the surface adsorbed compound. In the present case, the following parameters were used: Melting Points $\left(\mathrm{T}_{\mathrm{m}}\right)^{27} \mathrm{ZrCl}_{4}, 437{ }^{\circ} \mathrm{C} ; \mathrm{ZrBr}_{4}, 450{ }^{\circ} \mathrm{C}$ and $\mathrm{ZrI}_{4}, 499{ }^{\circ} \mathrm{C}$; $280 \mathrm{MPa}$ for the yield stress of Zry-4 $(\sigma)$ (measured by the authors), $3.18 \times 10^{-10} \mathrm{~m}$ for the atomic diameter of circonium $^{28}$ (a), and $25^{\circ} \mathrm{C}$ for the working temperature (T). The mechanism predicts a crack propagation rate of between $1.6 \times 10^{-4}$ and $3.9 \times 10^{-5} \mathrm{~m} / \mathrm{s}$.

As mentioned above, in the present work, it was not possible to resolve the IG attack rate and TG cpr, but $\mathrm{Cox}^{29}$ reported crack propagation rates for transgranular cracking between $1 \times 10^{-6} \mathrm{~m} / \mathrm{s}$ and $1.5 \times 10^{-4} \mathrm{~m} / \mathrm{s}$ in $5 \% \mathrm{NaCl}$ solutions; values close to those predicted by this mechanism. On the other hand, the activation energy predicted by the Surface-Mobility SCC mechanism for iodide solutions $(15 \mathrm{~kJ} / \mathrm{mol})$ is close to the value reported by Speidel $^{30}$ for Zry-4 DCB specimens in KI aqueous solutions in the 20$100{ }^{\circ} \mathrm{C}$ temperature range $(16,7 \mathrm{~kJ} / \mathrm{mol})$.

\section{Conclusions}

From he present work, the following conclusions can be drawn:

- Polarization curves of Zry-4 in $1 \mathrm{M} \mathrm{NaCl}, 1 \mathrm{M} \mathrm{KBr}$ and $1 \mathrm{M} \mathrm{KI}$ aqueous solutions showed the existence of a pitting potential characteristic of each solution and independent of temperature between 20 and $90{ }^{\circ} \mathrm{C}$.

- SCC of Zry-4 in $1 \mathrm{M} \mathrm{NaCl}, 1 \mathrm{M} \mathrm{KBr}$ and $1 \mathrm{M} \mathrm{KI}$ solutions was only observed at potentials above the respective pitting potentials in each solution. Crack morphology was found to be mixed: intergranular initiation was followed by transgranular propagation.

- The crack velocity increased slightly with applied potential above the pitting potential.

- The strain rate had an accelerating effect on the crack propagation rate, without changing the crack morphology.

- The crack velocity increased slightly with temperature.

- The steps in the process are as follow: first electrochemical breakdown of the passive film, followed by intergranular cracking; then a transition from intergranular to transgranular cracking and a rapid transgranular propagation

- The Surface-Mobility SCC accounts for the results obtained in the present work, as well as activation energies reported in the literature.

\section{Acknowledgment}

The financial support of the Consejo Nacional de Investigaciones Científicas y Técnicas (CONICET) and of the FONCYT, Secretaría de Ciencia y Tecnología, from Argentina, is acknowledged.

\section{References}

1. Yau, T.L. "Stress-Corrosion Cracking of Zirconium Alloys", in Stress-Corrosion Cracking, Materials Performance and Evaluation, R. Jones Ed., ASM International, 
Material Park, Oh, USA, p. 299, 1996.

2. Cox, B. Corrosion, v. 29, n. 4, p. 157-166, 1973.

3. Dunham, J.T.; Kato, H.G. U. S. Bureau of Mines Report BM-RI 5784, 1961.

4. Thomas, K.C.; Allio, R.J. Nucl. Appl., v. 1 n. 6, p. 252258, 1965.

5. Bogoyavlenskii, V.L.; Filiminov, A.V.; Shevtsov, A.P. Zashchita Metallov., v. 17, n. 3, p. 259-265, 1981.

6. Elayaperumal, K.; De, P.K.; Balachandra, J. Corros. Sci., v. 11, p. 579-589, 1971.

7. Yau, T.L. Corrosion, v. 39, n. 5, p. 167-174, 1983.

8. Yau, T.L. Corrosion, v. 44, n. 10, p. 745-749, 1988.

9. Wood, J.C.; Surette, B.A. London, I.M., Baird, J., J. Nucl. Mat., v. 57, p. 155-179, 1975.

10. Cox, B. Corrosion, v. 28, n. 6, p. 207-217, 1972.

11. Jones, R. Stress-Corrosion Cracking, Materials performance and evaluation, ASM International, Materials Park, Ohio,p. 302, 1996.

12. Cragnolino, G. Corrosión bajo tensiones del circonio y de sus aleaciones en presencia de cloruros, Ph.D. Thesis, FCEyN-UBA, Argentina, 1975.

13. Galvele, J.R.; De Micheli, S.M. de; Muller, I.L.; Wexler, S.B. de; Alanis, I.L. Localized Corrosion, R.W. Staehle, B.F. Brown, J. Kruger and A. Agrawal Eds., NACE, Houston, p. 580-599, 1974.

14. Pourbaix, M. Atlas of Electrochemical Equilibria in Aqueous Solutions, NACE, Houston, Texas, 1974.

15. Gardiazábal, I.; Córdova, R.; Gómez, H.; Schrebler, R. J.Electroanal.Chem., v. 240, p. 299-308, 1988.

16. Galvele, J.R.; Torresi, R.M.; Carranza, R.M. Corros.Sci., v. 31, p. 563-571, 1990.

17. Beck, T.R. "A review: pitting attack of titanium alloys" in Localized Corrosion, NACE 3, R. Staehle, B. Brown, J. Kruger, A. Agrawal, Eds., NACE, Houston, Texas, 1974. 18. Mankowski, G.; Roques, Y.; Chatainier,G.; Dabosi, F. Br. Corros. J., v. 19 n. 1, p. 17-22, 1984.

19. Serebrinsky, S.A.; Duffó, G.S.; Galvele, J.R. Corros. Science, v. 41, p. 191-195, 1999.

20. Serebrinsky. S.A. Efecto de la velocidad de deformación sobre la velocidad de propagación de fisuras en corrosión bajo tensión, Ph.D. Thesis, Instituto Balseiro, Univ. Nac. Cuyo, 2000.

21. Yau, T.L.; Maguire, M. Corrosion, v. 40, 289-296, 1984.

22. Farina, S.B., Corrosión bajo tensión de circonio y aleaciones en soluciones de halogenuros. Ms. Sci. Thesis. Instituto de Tecnología Prof. Jorge Sábato, UNSAM, Argentina, 2001.

23. Galvele, J.R. Corros. Sci., v. 27, n. 1, p. 1-33, 1987.

24. Gjostein N.A. Surfaces and interfaces-i, J. J. Burke, N. L. Reed y V. Weiss Eds., Syracuse University Press, Syracuse, p. 271-304, 1967.

25. Rhead G.E. Surf. Sci., v. 15, p. 353-57, 1969.

26. Rhead G.E. Surf. Sci., v. 22, p. 223-28, 1970.

27. West, R.C. Handbook of Chemistry and Physics, $79^{\text {th }}$ Edition, CRC Press, The Chemical Rubber Co., Cleveland, Ohio, p. 4.98, 1998/99.

28. Pauling, L. The Nature of Chemical Bond, $3^{\text {rd }}$ Ed., Cornell University Press, Ithaca, New York, p. 410, 1960.

29. Cox, B. Review on Coatings and Corrosion, v. 1, p. 367-422, 1975.

30. Speidel, M.O. "Stress corrosion cracking of zirconium alloys", presentation to ASTM Committee E-24-Sub IV, Los Angeles, 1971 and ARPA-Handbook on SCC, R.W. Staehle and M.O. Speidel Eds. (draft). 